\title{
Effects of Cataract Surgery on Lacrimal Drainage System
}

\author{
Rahman $M Z^{1}$, Hasan $Z^{2}$, Aleem $M A^{3}$, Begum $N^{4}$
}

\begin{abstract}
Introduction: Complaining of tearing was found in some of the patients after cataract surgery (both Phacoemulsification and Small Incision Cataract Surgery) for age related cataract, among male and female patients with an increased incidence among female and more elderly patients. Secondary acquired lacrimal drainage obstruction has been proposed to develop due to different causes like infections and inflammation of the lacrimal drainage system. Watering eyes are observed after cataract surgery may be due to surgical trauma, inflammation of the anterior segment of the operated eye, frequent use of topical medications during the post operative periods and less forceful blinking by the patients in early postoperative days.
\end{abstract}

Objective: To determine the effects of cataract surgery (both Phacoemulsification and Small Incision Cataract Surgery) on lacrimal drainage system in eyes with age related cataract.

Methods: This cross-sectional study was performed on 100 eyes of 100 patients with age related cataract. Among the patients, 64 were male and 36 were female. All the patients were Armed Forces personnels (both serving, retired and civilians) and their parents. The average age of the patients were $61.6 \pm 8.92$ years ranging from 51 to 80 years. According to age, the patients were divided in three age-group (51-60 years; $61-70$ years; $71-80$ years). The patients were equally divided in two groups. In group-I $(n=50)$, patients were done Phacoemulsification and posterior chamber intraocular lens (PCIOL) implantation and in group-II $(n=50)$, patients were done Small Incision Cataract Surgery (SICS) and $\mathrm{PCIOL}$ implantation in one eye. All the patients were operated under peribulbar anesthesia. Included patients had Fluorescein Disappearance
Test (FDT) and Taste test duration of $\leq 5.7$ minutes in both eyes before operation. Tear drainage function tests were repeated for one week and one month after surgery in both eyes and obtained data were compared.

Results: The incidence of watering eyes after phacoemulsification surgery in eyes treated for age related cataract was $17 \%$ at the end of first week and $09 \%$ after one month. The mean taste test duration time was $3.83 \pm 0.76$ minutes before surgery, $5.33 \pm 2.45$ minutes after a week and $4.27 \pm 1.53$ minutes one month after surgery. After SICS the incidence of lacrimal drainage impairment was 19\% at the end of first week and $12 \%$ after one month. The mean Taste test duration time was $3.83 \pm 0.76$ minutes before surgery, $5.62 \pm 2.84$ minutes after a week and $4.36 \pm 1.85$ minutes one month after surgery. However, more number of elderly patients developed watering eyes than the lower age group. Among the patients, from 71-80 years age group, 05 patients (19.23\%) developed watering eyes. There was slight difference between male and female in complaining of tearing after operation. Out of 64 male, 11 patients (approximately 17.18\%) were observed watering eyes in first week follow up. Among 36 female, 07 patients (approximately $19.44 \%$ ) complained of watering in first week follow up. No difference of watering was observed in respect of socio-economic conditions. No post operation complains of watering eyes was observed in the sound eyes (non-operated) of the patients.

Conclusion: Watering eyes may develop cataract surgery (both Phacoemulsification and SICS) in eyes with age related cataract, among male and female patients with an increased incidence among female and more elderly patients.

1. Lt Col Md Zahidur Rahman, MBBS, MCPS, DO, FCPS, Classified Spl in Ophthalmology, BNS Patenga, Newmooring, Chittagong; 2. Col Zulfikar Hasan, MBBS, DO, FCPS, Classified Ophthalmologist, CMH, Bogra; 3. Col M A Aleem, MBBS, FCPS, Classified Anaesthesiologist, BNS Patenga, Newmooring, Chittagong; 4. Lt Col Nasima Begum, MBBS, DGO, FCPS, Classified Gynaecologist, BNS Patenga, Newmooring, Chittagong. 
Key-words: Lacrimal drainage, cataract surgery, phacoemulsification, SICS (Small Incision Cataract Surgery).

\section{Introduction}

The commonest symptom of lacrimal disorders is watering eyes ${ }^{1}$. Lacrimation is defined as the sign of over flow of tears, and may be caused by hypersecretion secondary to ocular inflammation, conjunctival and corneal surface diseases, trauma including surgical trauma to the conjunctiva and cornea. Epiphora is defined as defective drainage due to compromise of the lacrimal drainage system secondary to malposition of lacrimal puncta, obstruction along the lacrimal drainage system or lacrimal pump failure ${ }^{2}$. Complaining of tearing was found in some of the patients after Phacoemulsification and SICS for senile cataract. Decreased drainage (due to inflammation after surgery) or increased secretion of tear (due to conjunctival and corneal trauma during surgery) or a combined mechanism could be considered for the etiology of this symptom. Bartley proposed an etiologic classification system for Secondary Acquired Lacrimal Drainage Obstruction (SALDO) which included infectious and inflammatory causes ${ }^{3}$.

Tearing has been explained to be a sign of conjunctival inflammation and adverse ocular effect of topical ocular medications ${ }^{4}$. The term Primary Acquired Nasolacrimal Duct Obstruction (PANDO) was explained by Linberg and McCormik in 1986 as idiopathic inflammation and fibrosis of nasolacrimal duct resulting in its partial stenosis or complete obstruction and its incidence was found to be higher in older individuals ${ }^{5}$. Most of the pathologic specimens obtained during dacryocystorrhinostomy (DCR) from the PANDO cases revealed no significant pathology but a chronic inflammatory process $^{6,7,8,9}$. The clinical evaluation of the lacrimal drainage system was originally outlined by Lester Jones. The Fluorescein Disappearance Test (FDT) is useful for assessing the normal or any impairment of tear drainage using a drop of sterile $2 \%$ fluorescein solution or a moistened fluorescein strip $^{10}$. This study was performed to evaluate the effect of cataract surgery on lacrimal drainage system of eyes treated for senile cataract at BNS Potenga, Bangladesh Navy, Chittagong from January 2013 to May 2014.

\section{Methods}

In this cross-sectional study, 100 eyes of 100 patients with age related cataract were operated and observed for complain of watering eyes. Among them, 64 were male and 36 were female. All the patients were Armed Forces personals (serving, retired, and civilians) and their parents. The average age of the patients were $61.6 \pm 8.92$ years ranging from 51 to 80 years. According to age, the patients were divided in three age-group (51-60 years; $61-70$ years; $71-80$ years). The patients were equally divided in two groups. In group-I $(\mathrm{n}=50)$, patients were done Phacoemulsification surgery in one eye and in group-II $(n=50)$ SICS were done in one eye. Lacrimal drainage function was tested by Taste test $^{11,12}$ and Fluorescein Disappearance Test (FDT) ${ }^{13}$ before operation, at the end of one week and one month after operation in both eyes of each patient. Taste test was performed separately for each eye with one hour interval by instillation of chloramphenicol $0.5 \%$ drop in the inferior fornix which was repeated after 15 seconds. While in the semi-sitting position, the patients were asked to report any bitter taste when noticed. FDT was performed by simultaneous application of moistened fluorescein strips in the inferior fornices of both eyes after topical anesthesia; the disappearance of dye were observed and compared for 06 minutes using cobalt blue illumination. The included patients had symmetric Dye Disappearance and positive Taste test duration of $\leq 5.7$ minutes in either eye before the operation. Poor responders to the taste of chloramphenicol and cases with a history of previous trauma or surgical intervention on the eyes and ocular adnexa were excluded from the study. Eyes with poor FDT combined with no positive response to Taste test within 11 minutes, were defined to have lacrimal drainage impairment and also excluded from the study. Suture-less Phacoemulsification/SICS and PCIOL implantation were performed by one surgeon (first author) in all patients under peribulbar anesthesia. $5 \%$ povidone solution was used for preparation of eyelids and conjunctiva (two drops for one minute duration) just before the surgery. In case of phacoemulsification surgery, superior $2.8 \mathrm{~mm}$ clear corneal incisions were done. Foldable acrylic lenses were implanted in the capsular bag. In case of SICS, $6-7 \mathrm{~mm}$ superior limbal incision were done. Polymethaylmethacrylate (PMMA) lenses were implanted in the capsular bag. Inferior fornix sub-conjunctival injection 
of $20 \mathrm{mg}$ gentamycin and $2 \mathrm{mg}$ of betamethasone was given at the end of surgery. Eye pads were applied in all cases for 24 hours. On the 1st post-operative day morning eye pad was removed and cleaned with sterile cotton buds and examined under slit lamp microscope. The patients were instructed to put on topical moxifloxacin $0.5 \%$ every 6 hours and prednisolone acetate $1 \%$ drops every 2 hours and then subsequently reduced for three to four weeks in the post-operative period according to the severity of ocular inflammation. Washing the face and head was allowed after 07 days from the operation time. Statistical comparison was performed between the Taste test time durations obtained in the pre- and post-operative periods for both eyes.

\section{Results}

The study was performed on 100 eyes of 100 patients who remained for complete follow up, including 36 females and 64 males. The average age of the patients were $61.6 \pm 8.92$ years ranging from 51 to 80 years. The incidence of watering in eyes being treated for age related cataract was $17 \%$ at the end of 1 st week and $09 \%$ one month after phacoemulsification surgery; the mean Taste test duration time was $3.83 \pm 0.76$ minutes before surgery, $5.33 \pm 2.45$ minutes at the end of 1 st week and $4.27 \pm 1.53$ minutes one month after surgery. In SICS, complain of watering eyes were $19 \%$ at the end of 1 st week and $12 \%$ one month after operation, the mean taste test duration time were $3.83 \pm 0.76$ minutes before surgery, $5.62 \pm 2.84$ minutes at the end of 1 st week and $4.36 \pm 1.85$ minutes one month after surgery. However, more number of elderly patients complained of watering eyes than the lower age group. Among the patients, from 71-80 years age group, 05 patients (19.23\%) developed watering eyes. There was slight difference between male and female in complaining of tearing after operation. Out of 64 male, 11 patients (approximately 17.18\%) were observed watering eyes in first week follow up. Among 36 female, 07 patients (approximately 19.44\%) complained of watering in first week follow up. No post-operation watering eyes were observed in the fellow eyes (non-operated) of the patients.

Table-I shows number of patients in different age groups and number (and percentage) of patients developed watering eyes after cataract surgery.

Table-II: Shows numbers of male and female were operated in both groups, and number (and percentages) of male and female patients complained of watering eyes in first week follow up.

Table-III: Shows lacrimal drainage Taste test duration times in the operated and fellow eyes of the patients before and after Phacoemulsification surgery.

Table-IV: Shows lacrimal drainage Taste test duration times in the operated and fellow eyes of the patients before and after SICS.

Table-I: Number of patients in different age groups and number (and percentage) of patients developed watering eyes after cataract surgery.

\begin{tabular}{|c|c|c|}
\hline Age group & $\begin{array}{c}\text { No of patients } \\
\text { operated }\end{array}$ & No of patients(\%) developed lacrimal drainage impairment \\
\hline $51-60$ years & 23 & $04(17.39 \%)$ \\
\hline $61-70$ years & 51 & $09(17.64 \%)$ \\
\hline $71-80$ years & 26 & $05(19.23 \%)$ \\
\hline
\end{tabular}

Table-II: Number of male and female patients was operated in both groups, and number (and percentages) of male and female complained of watering eyes in first week follow up.

\begin{tabular}{|c|c|c|c|c|}
\hline Number $(n=100)$ & $\begin{array}{c}\text { No of male } \\
\text { operated }\end{array}$ & $\begin{array}{c}\text { No of female } \\
\text { operated }\end{array}$ & $\begin{array}{c}\text { No of male complained } \\
\text { of tear drainage } \\
\text { impairment }\end{array}$ & $\begin{array}{c}\text { No of female complained } \\
\text { of tear drainage } \\
\text { impairment }\end{array}$ \\
\hline Group-I $(n=50)$ & 38 & 12 & $06(15.78 \%)$ & $02(16.67 \%)$ \\
\hline Group-II $(n=50)$ & 26 & 24 & $05(19.23 \%)$ & $05(20.33 \%)$ \\
\hline
\end{tabular}


Table-III: Lacrimal drainage Taste test duration times in the operated and sound eyes of the patients before and after Phacoemulsification surgery.

\begin{tabular}{|c|c|c|c|c|c|c|}
\hline $\begin{array}{c}\text { Number } \\
\mathrm{n}=50\end{array}$ & 1 & 2 & 3 & 4 & 5 & 6 \\
\hline Groups-I & $\begin{array}{c}\text { Operated } \\
\text { eyes before } \\
\text { surgery }\end{array}$ & $\begin{array}{c}\text { Operated } \\
\text { eyes one } \\
\text { week after } \\
\text { surgery }\end{array}$ & $\begin{array}{c}\text { Operated } \\
\text { eyes one } \\
\text { month after } \\
\text { surgery }\end{array}$ & $\begin{array}{c}\text { Fellow } \\
\text { eyes before } \\
\text { surgery }\end{array}$ & $\begin{array}{c}\text { Fellow } \\
\text { eyes one } \\
\text { week after } \\
\text { surgery }\end{array}$ & $\begin{array}{c}\text { Fellow } \\
\text { eyes one } \\
\text { month after } \\
\text { surgery }\end{array}$ \\
\hline $\begin{array}{c}\text { Mean } \pm S D \\
\text { (minutes) }\end{array}$ & $3.83 \pm 0.76$ & $5.33 \pm 2.45$ & $4.27 \pm 1.53$ & $3.84 \pm 0.78$ & $3.86 \pm 0.79$ & $3.85 \pm 0.76$ \\
Minimum & 2.24 & 2.93 & 2.31 & 2.22 & 2.23 & 2.21 \\
Maximum & 5.37 & 08.42 & 06.27 & 5.46 & 5.49 & 5.44 \\
\hline
\end{tabular}

Table-IV: Lacrimal drainage Taste test duration times in the operated and fellow eyes of the patients before and after SICS.

\begin{tabular}{|c|c|c|c|c|c|c|}
\hline $\begin{array}{c}\text { Number } \\
\mathrm{n}=50\end{array}$ & 1 & 2 & 3 & 4 & 5 & 6 \\
\hline Groups-II & $\begin{array}{c}\text { Operated } \\
\text { eyes before } \\
\text { surgery }\end{array}$ & $\begin{array}{c}\text { Operated } \\
\text { eyes one } \\
\text { week after } \\
\text { surgery }\end{array}$ & $\begin{array}{c}\text { Operated } \\
\text { eyes one } \\
\text { month after } \\
\text { surgery }\end{array}$ & $\begin{array}{c}\text { Fellow } \\
\text { eyes before } \\
\text { surgery }\end{array}$ & $\begin{array}{c}\text { Fellow } \\
\text { eyes one } \\
\text { week after } \\
\text { surgery }\end{array}$ & $\begin{array}{c}\text { Fellow } \\
\text { eyes one } \\
\text { month after } \\
\text { surgery }\end{array}$ \\
\hline $\begin{array}{c}\text { Mean } \pm S D \\
\text { (minutes) }\end{array}$ & $3.83 \pm 0.76$ & $5.62 \pm 2.84$ & $4.36 \pm 1.85$ & $3.83 \pm 0.79$ & $3.84 \pm 0.77$ & $3.84 \pm 0.76$ \\
Minimum & 2.25 & 2.97 & 2.34 & 2.23 & 2.25 & 2.20 \\
Maximum & 5.35 & 8.57 & 6.85 & 5.48 & 5.30 & 5.25 \\
\hline
\end{tabular}

\section{Discussion}

This study shows that functional impairment of lacrimal drainage can developed after cataract surgery (both phacoemulsification and SICS) in eyes with age-related cataract, irrespective of socio-economic conditions, with a slight increase incidence among female and more elderly patients ${ }^{5}$. Two mechanisms can be proposed for the development of watering eyes after cataract surgery; 1 . Inflammation of the ocular surface and anterior segment of the operated eye could extend into the lacrimal drainage system and cause functional impairment of lacrimal drainage and SALDO. Surgical trauma, subconjunctival injections and specially preparation of eyelids and conjunctiva with povidone solution before surgery could affect the extent of ocular inflammation too through leakage of povidone solution into the drainage system. 2. Less forceful blinking by the patient in the early post-operative period might cause weakness of lacrimal pump that could simulate a functional occlusion in an already compromised lacrimal system of old age (de-epithelialization within the lacrimal drainage system and higher incidence of PANDO in individuals aged 50 to 70$)^{4}$. Complaining of watering eyes are a bit more in SICS than Phacoemulsification surgery, could be explained by the fact that this group of patients develop more reflex lacrimation due to conjunctival and limbal incisional injury. However to find out the difference of impairment of lacrimal drainage between two methods of surgery was not the aim of this study. Improvement of watering one month post-operation in comparison to one week post-operation indicates that the effect of predisposing factors had gradually decreased. However, more number of elderly patients developed watering eyes than the lower age-group due to already compromised lacrimal drainage system in old age. Slight difference in watering after cataract surgery was observed among male and female patients. The result of this study is near to similar study done by Masoud Aghajani. He carried a study in Feitz Hospital Iran and showed that impairment of lacrimal drainage is $19 \%$ after one week and $11 \%$ after one month postoperatively. In his study Taste test duration was $3.83 \pm 0.67$ minutes before surgery and $5.79 \pm 2.82 \mathrm{~min}$ one week after surgery ${ }^{14}$. Although Taste test is a subjective test with false negatives ${ }^{10,11}$ and FDT is a gross test ${ }^{12}$, there may be no better ways for functional evaluation of the lacrimal drainage system. Exclusion of poor responders to Taste test and using these tests in 
combination might have decreased the faulty evaluations. Over secretion of tear as a cause of tearing was not evaluated in this study. Further studies may identify the pathologic reason for the development of watering can help us in its prevention and treatment.

\section{Conclusions}

The results of this study indicate that watering eyes may develop in some patients after cataract surgery for age related cataract irrespective of methods of surgical procedures. Male or female can be affected, with an increased incidence among female and elderly patients. Peribulbar anesthesia, use of povidone solution before operation to prevent infection, sterile ocular inflammation due to surgical trauma, prolonged and frequent use of topical medications and patient's fear of forceful blinking etc. could be the cause of watering eyes after cataract surgery. Functional impairment of lacrimal drainage in old age acts as a predisposing factor in this regard.

\section{Recommendation}

Patients undergoing cataract surgery may be informed about the possibility of watering eyes after surgery during preoperative counseling using the easy and understandable language, so that patient can be aware of the condition to avoid or reduce postoperative patient's dissatisfaction.

\section{References}

1. Person's Diseases of the Eye; Lacrimal drainage system; 21st edn; 2011. P.464.

2. Jack J Kanski; Brad Bowling; Clinical ophthalmology; Lacrimal drainage system; 7th edn-2007; p 66-77.

3 Bartley GB. Ophthal Plast Reconstr Surg 1993; 9(1):11-26.

4. Garcia-Ferrer F, Schwab I, Shatler D. Conjunctiva. In: Riordan-Eva P, Asbury T, Whitcher J, editors. Vaughan \& Asbury's General Ophthalmology (Paperback). New York: McGraw-Hill Medical; 2003. p.101-2.
5. Linberg JV, McCormick SA. Primary acquired nasolacrimal duct obstruction. A clinicopathologic report and biopsy technique. Ophthalmology 1986; 93(8):1055-63.

6. Bernardini FP, Moin M, Kersten RC, Reeves D, Kulwin DR. Routine histopathologic evaluation of the lacrimal sac during dacryocystorhinostomy: how useful is it? Ophthalmology 2002; 109(7):1214-7.

7. Lee-Wing MW, Ashenhurst ME. Clinicopathologic analysis of 166 patients with primary acquired nasolacrimal duct obstruction. Ophthalmology 2001; 108(11):2038-40.

8. Paulsen FP, Thale AB, Maune S, Tillmann BN. New insights into the pathophysiology of primary acquired dacryostenosis. Ophthalmology 2001; 108(12):2329-36.

9. Tucker N, Chow D, Stockl F, Codere F, Burnier M. Clinically suspected primary acquired nasolacrimal duct obstruction: clinicopathologic review of 150 patients. Ophthalmology 1997; 104(11):1882-6.

10. American Academy of Ophthalmology; Lacrimal out flow evaluation; Chapter-13; Section-7;20112012; p258.

11. Katowitz J, Low J. Evaluation of epiphora. In: Tasman W, Jaeger E, editors. Duane's Clinical Ophthalmology: Philadelphia: Lippincott Williams \& Wilkins; 2001.

12. Hornblass A, Herschorn B. Lacrimal diagnosis. In: Nesi F, Levine M, Lisman R, editors. Smith's Ophthalmic Plastic and Reconstructive Surgery. Mosby; 1998. p. 645-6.

13. Kersten RC, Codere F, Dailey RA, Garrity JA, Nerad JA, Popham JK. Evaluation and management of tearing patient. Orbit, Eyelids, and Lacrimal System. American Academy of Ophthalmology; 2004. p. 268-9.

14. Masuod Aghajani; Impairment of Lacrimal Drainage after cataract surgery; Journal of Research in Medical science; Vol. 12; Issue 1;2007. 